\title{
ESTUDO DE SÍNTESE E TRANSIÇÃO ENTRE AS FASES ZEOLÍTICAS SODALITA E CANCRINITA
}

\author{
C. G. M. SANTOS ${ }^{2,3}$, F. A. C. M. PASSOS ${ }^{2,3}$, A. A. S. SILVA ${ }^{1,2}$, C. N. BARBATO ${ }^{3}$, J. A. SAMPAIO ${ }^{2}$ e F. M. S. \\ GARRIDO $^{1}$, F. A. N. G SILVA ${ }^{1}$ \\ ${ }^{1}$ Instituto de Química/Universidade Federal do Rio de Janeiro. \\ ${ }^{2}$ Centro de Tecnologia Mineral (CETEM/MCTI). \\ ${ }^{3}$ Escola de Química/Universidade Federal do Rio de Janeiro. \\ cgsantos@cetem.gov.br, asoeiro@cetem.gov.br, carla.barbato@iq.com.br, jsampaio@cetem.gov.br, \\ chico@iq.ufrj.br,fnogueira@iq.ufrj.br
}

Artigo submetido em novembro/2013 e aceito em fevereiro/2014

DOI: http://dx.doi.org/10.15628/holos.2014.1823

\section{RESUMO}

Para a síntese hidrotermal das zeólitas foi utilizado como fonte de alumínio e de silício o caulim da região Borborema-Seridó (PB/RN) in natura e tratado termicamente a 500, 700 e $900^{\circ} \mathrm{C}$ por 2 horas. As amostras in natura e ativadas termicamente foram caracterizadas por difração de raios $X$ e espectroscopia no infravermelho. A síntese da fase sodalita e a transição para a fase cancrinita foram investigadas em diferentes condições estequiométricas. Na síntese $A$, a razão molar entre caulinita/metacaulinita, reagentes alcalinos ( $\mathrm{Na}_{2} \mathrm{CO}_{3}$ e $\mathrm{NaOH}$, respectivamente) e água foi de 1:8:2:143, e na síntese B a razão foi de 1:1:10:65.
As sínteses foram realizadas em vasos de pressão de aço inox na temperatura de $170^{\circ} \mathrm{C}$ por 1 e $4 \mathrm{~h}$. Os produtos obtidos foram caracterizados por difração de raios $\mathrm{X} e$ espectroscopia vibracional no infravermelho. A fase sodalita, com boa pureza, foi obtida com caulim ativado termicamente, na síntese A por $4 \mathrm{~h}$. No entanto, a transformação do caulim bruto em sodalita ocorre preferencialmente nas condições da síntese B. No caso do caulim calcinado a $900^{\circ} \mathrm{C}$ a fase cancrinita foi formada nas condições da síntese B. As zeólitas formadas também foram caracterizadas por microscopia eletrônica de varredura.

PALAVRAS-CHAVE: Síntese hidrotérmica, zeólitas, cancrinita, sodalita, caulim.

\section{STUDY OF SYNTHESIS AND TRANSITION BETWEEN THE ZEOLITIC PHASES SODALITE AND CANCRINITE}

\begin{abstract}
For the hydrothermal synthesis of the zeolites, kaolin from Borborema-Serido (RN/PB) was used as the source of aluminum and silicon in its natural form and thermal activated at 500, 700 and $900{ }^{\circ} \mathrm{C}$ for 2 hours. The natural and thermal activated samples were characterized by $X$ ray diffraction and infrared spectroscopy. The synthesis of the phase sodalite and its transition to the cancrinita phase were investigated in different stoichiometric conditions. To the synthesis $A$, the rate between caulinite/metacaulinite, alkaline reagents $\left(\mathrm{Na}_{2} \mathrm{CO}_{3}\right.$ and $\mathrm{NaOH}$, respectively) and water was 1:8:2:143. To the synthesis $B$, the rate was $1: 1: 10: 65$. The synthesis were
\end{abstract}

run in a stainless steel vessel at the temperature of 170 ${ }^{\circ} \mathrm{C}$ for 1 and 4 hours. The products obtained were characterized by $X$ ray diffraction and infrared spectroscopy. The sodalite phase with good purity was obtained with thermally activated kaolin, in the synthesis A for $4 \mathrm{~h}$. However, conversion of kaolin in natura to sodalite preferably occurs under conditions of synthesis B. In the case of kaolin calcined at $900^{\circ} \mathrm{C}$ the cancrinite phase was formed under the conditions of the synthesis B. Zeolites formed were also characterized by scanning electron microscopy.

KEYWORDS: Hydrothermal synthesis, cancrinite, sodalite, kaolin. 


\section{INTRODUÇÃO}

A poluição química de natureza orgânica ou inorgânica, decorrente de despejos industriais contaminados por metais pesados é um dos problemas graves que afetam o meio ambiente (AGUIAR, et. al. 2002). A remoção desses metais pode ser feita por diferentes processos, tais como a ultrafiltração; a remoção por biomassa com plantas aquáticas; utilização de matéria orgânica morta; emprego de microrganismos; a precipitação de metais por solos incinerados; a precipitação e flotação de sulfetos, inclusive o uso de resinas de troca-iônica (AGUIAR et. al. 2002).

É conhecida a aplicação de resinas de troca iônica em indústrias para a remoção de íons em água industrial ou em águas de caldeira e na purificação de substâncias orgânicas e inorgânica. Por outro lado, a utilização desse material no tratamento de efluentes contendo metais pesados é economicamente inviável. Desse modo, várias pesquisas são desenvolvidas com o propósito de se empregar trocadores iônicos naturais, a exemplo, os aluminossilicatos, que possuem baixo custo e alta disponibilidade.

A sílica ocorre na natureza com a fórmula empírica aproximadamente igual a $\mathrm{SiO}_{2} . \mathrm{A}$ substituição parcial de átomos de silício por alumínio dá origem ao grupo dos aluminossilicatos. Os principais componentes deste grupo são as argilas e as zeólitas.

As zeólitas podem ser definidas como aluminossilicatos cristalinos com uma estrutura tridimensional composta por um conjunto de cavidades ocupadas por grandes íons e moléculas de água, ambos com considerável liberdade de movimento, permitindo a troca iônica e uma hidratação reversível (SHINZATO, 2007).

A aplicação de aluminossilicatos na remoção de metais pesados vem sendo muito estudada devido ao baixo custo, a fácil obtenção e a possibilidade de reutilização destes materiais (SILVA FILHO et al., 2007). A cancrinita e a sodalita são consideradas materiais zeolíticos devido a sua estrutura porosa, possuem alta capacidade de adsorção, conferindo a esses sistemas a possibilidade de aplicação em processos de adsorção (MALDONADO et al., 2013; GRADER e BUHL, 2013). Assim, o propósito deste trabalho, é avaliar as condições de síntese e a transição entre as fases sodalita e cancrinita a fim de compreender, em trabalhos futuros, a influência dessas fases em processo de adsorção de metais pesados.

\section{MATERIAIS E MÉTODOS}

O estudo de síntese e transição entre as fases sodalita e cancrinita iniciou-se com a digestão do caulim (principal fonte de sílica na bauxita) em solução de hidróxido de sódio, utilizando carbonato de sódio como fonte de carbonato. Para síntese hidrotermal das fases zeolíticas o caulim utilizado foi proveniente da região Borborema-Seridó (PB/RN).

Desse modo, uma alíquota homogênea de caulim foi peneirada a úmido em um peneirador vibratório (684,5 rpm) equipado com peneiras de abertura de 74 e $37 \mu \mathrm{m}$. A fração menor que 37 $\mu \mathrm{m}$ foi filtrada, seca em estufa, quarteada e encaminhada à caracterização por difração de raios $\mathrm{X}$ e ao tratamento térmico a 500,700 e $900^{\circ} \mathrm{C}$ por $2 \mathrm{~h}$. 
As zeólitas foram sintetizadas sob diferentes condições estequiométricas que estão relacionadas na Tabela 1.

Tabela 1. Condições estequiométricas utilizadas na síntese das zeólitas.

\begin{tabular}{|c|c|c|c|c|}
\hline Síntese & Caulim: $\mathrm{Al}_{2} \mathrm{Si}_{2} \mathrm{O}_{5}(\mathrm{OH})_{4}$ & $\mathrm{Na}_{2} \mathrm{CO}_{3}$ & $\mathrm{NaOH}$ & $\mathrm{H}_{2} \mathrm{O}$ \\
\hline A & 1 & 8 & 2 & 143 \\
\hline B & 1 & 1 & 10 & 65 \\
\hline
\end{tabular}

As sínteses foram realizadas em vasos de pressão de aço inox com revestimento em teflon e, nos ensaios, em forno com rampa de aquecimento de $10^{\circ} \mathrm{C} / \mathrm{min}$, até atingir a temperatura de $170^{\circ} \mathrm{C}$, permanecendo nesta por 1 ou $4 \mathrm{~h}$.

Após o aquecimento, os vasos foram resfriados com água corrente e o produto obtido, após filtrado, foi lavado com água e seco em estufa. As amostras sintetizadas foram encaminhadas à difração de raios $X$ (DRX), espectroscopia vibracional no infravermelho (IV) e microscopia eletrônica de varredura (MEV).

Os difratogramas de raios $\mathrm{X}$ foram obtidos pelo método do pó. As análises foram realizadas

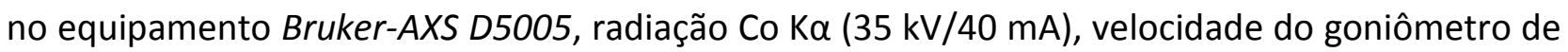
$0,02^{\circ}(2 \theta)$ por passo, com tempo de contagem de $1 \mathrm{~s}$ por passo e coletados de 5 a $80^{\circ}(2 \theta)$.

A análise por espectroscopia vibracional no infravermelho foi realizada no espectrofotômetro com transformada de Fourier, marca Nicolet Magna, com registros de 4000 a $400 \mathrm{~cm}^{-1}$, resolução de $4 \mathrm{~cm}^{-1}$, em pastilhas de $\mathrm{KBr}$.

A morfologia das partículas foi determinada em microscópio eletrônico de varredura Leica, modelo F440, em modo de alto vácuo. As amostras foram analisadas por elétrons retro espalhados.

\section{RESULTADOS E DISCUSSÃO}

O caulim é uma rocha de granulometria fina, constituída de material argiloso, normalmente com baixo teor de ferro, de cor branca ou quase branca (SILVA et al. 2011). Seu principal constituinte é a caulinita, podendo também ser chamado de caulim o produto resultante do beneficiamento dessa rocha. A fração menor que $37 \mu \mathrm{m}$ do caulim da região Borborema-Seridó, de origem primária, é essencialmente caulinítica, com composição química de $\mathrm{SiO}_{2}$ e de $\mathrm{Al}_{2} \mathrm{O}_{3}$ de 51,6 e 36,32\%, respectivamente (SANTOS et al., 2012). A lavra é artesanal, inicialmente a céu aberto, segundo os procedimentos característicos deste tipo de mineração, cujo principal mercado é a indústria de refratários e de cerâmica branca (SILVA et al. 2007).

A síntese de zeólitas, bem como a sua cristalização, é dependente do pH do meio reacional, que pode variar entre 8 e 13, por este motivo são utilizados reagentes alcalinos, uma vez que, a alcalinidade favorece a solubilização dos aluminosilicatos amorfos tornando-os, desse modo, mais reativos (MIGNONI, 2012). Neste contexto, a síntese da fase sodalita e a transição para a fase cancrinita foram investigadas sob duas condições estequiométricas, sínteses $A$ e $B$, como relacionado na Tabela 1. A escolha do reagente $\mathrm{NaOH}$ foi feita de modo a simular as condições reacionais do processo Bayer, uma vez que essas fases são formadas durante a digestão da bauxita 
para produção da alumina. Já o $\mathrm{Na}_{2} \mathrm{CO}_{3}$ foi utilizado como template para a formação das cavidades presente nas zeólitas.

O caulim foi submetido à calcinação em diferentes temperaturas com o objetivo de transformá-lo em metacaulinita e desse modo tornar os átomos de silício e de alumínio mais disponíveis para a síntese da sodalita (PAZ et al., 2010). No entanto, a reatividade da metacaulinita varia de acordo com a temperatura de seu tratamento térmico, assim como, a síntese das zeólitas, que também é afetada pelas características da caulinita ou metacaulinita utilizada (HELLER-KALLAI e LAPIDES, 2007).

Os espectros de IV das amostras de caulim bruto e do caulim calcinado a 500,700 e $900^{\circ} \mathrm{C}$ podem ser observados na Figura 1. Para a amostra calcinada a $500^{\circ} \mathrm{C}$, as bandas relacionadas à caulinita encontram-se alargadas, sendo observados pequenos deslocamentos de posição em relação ao caulim bruto. A avaliação dos resultados indica que, nessa temperatura, ocorreu apenas uma desestruturação parcial da estrutura cristalina da caulinita, dados de DRX corroboram esta interpretação (SANTOS et al., 2012).

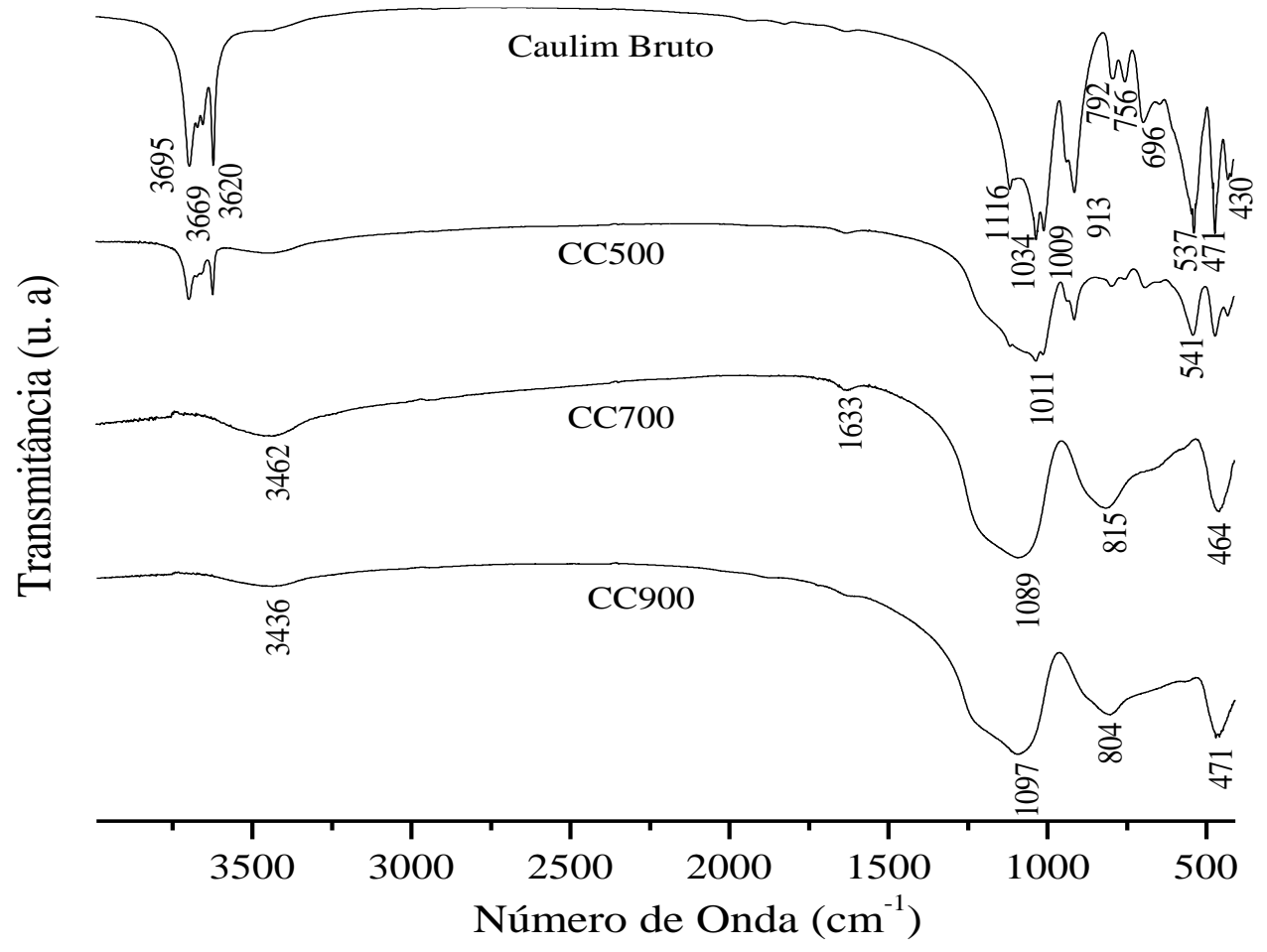

Figura 1: Infravermelho das amostras de caulim bruto e calcinado a 500, 700 e $900{ }^{\circ} \mathrm{C}$.

Para as amostras calcinadas a 700 e a $900^{\circ} \mathrm{C}$ observa-se o desaparecimento das bandas relacionadas aos estiramentos do grupo $\mathrm{O}-\mathrm{H}$, com destaque para a região entre 3.500 a $4.370 \mathrm{~cm}^{-}$ 1 , assim como, o alargamento e o deslocamento das outras bandas, em relação ao espectro do caulim bruto. De uma maneira geral, pode-se considerar que as amostras calcinadas a 700 e a $900^{\circ} \mathrm{C}$ possuem apenas ordem a curta distância, ou seja, um alto grau de desordem estrutural, sendo consideradas amorfas pela técnica de difração de raios X (SANTOS et al., 2012). Portanto, pode-se afirmar que nessas temperaturas ocorreu a completa transição da fase caulinita para a 
metacaulinita. Nos resultados de DRX, apresentados em trabalho anterior (SANTOS et al., 2012), observam-se apenas os picos relacionados aos minerais muscovita e quartzo, uma vez que, estes minerais expressam maior estabilidade térmica.

Os resultados de DRX para os produtos da Síntese A, por 1 hora, constam na Figura 2. Observa-se que o produto da síntese com caulim calcinado a $500^{\circ} \mathrm{C}$ possuem picos referentes à sodalita básica. No entanto, há também os picos relacionados ao mineral caulinita também estão presentes, além de serem observados picos, de menor intensidade, relacionados à muscovita e ao quartzo. Estes resultados indicam que, para esta síntese, a calcinação do caulim a $500^{\circ} \mathrm{C}$ não é adequada para a obtenção da fase sodalita com boa pureza. No caso dos difratogramas dos produtos da Síntese $\mathrm{A}$, por $1 \mathrm{~h}$, com o caulim calcinado a $700^{\circ} \mathrm{C}$ ou $900^{\circ} \mathrm{C}$, não são observados os picos relacionados à caulinita, o que indica a total conversão dessa fase, com a formação da sodalita.

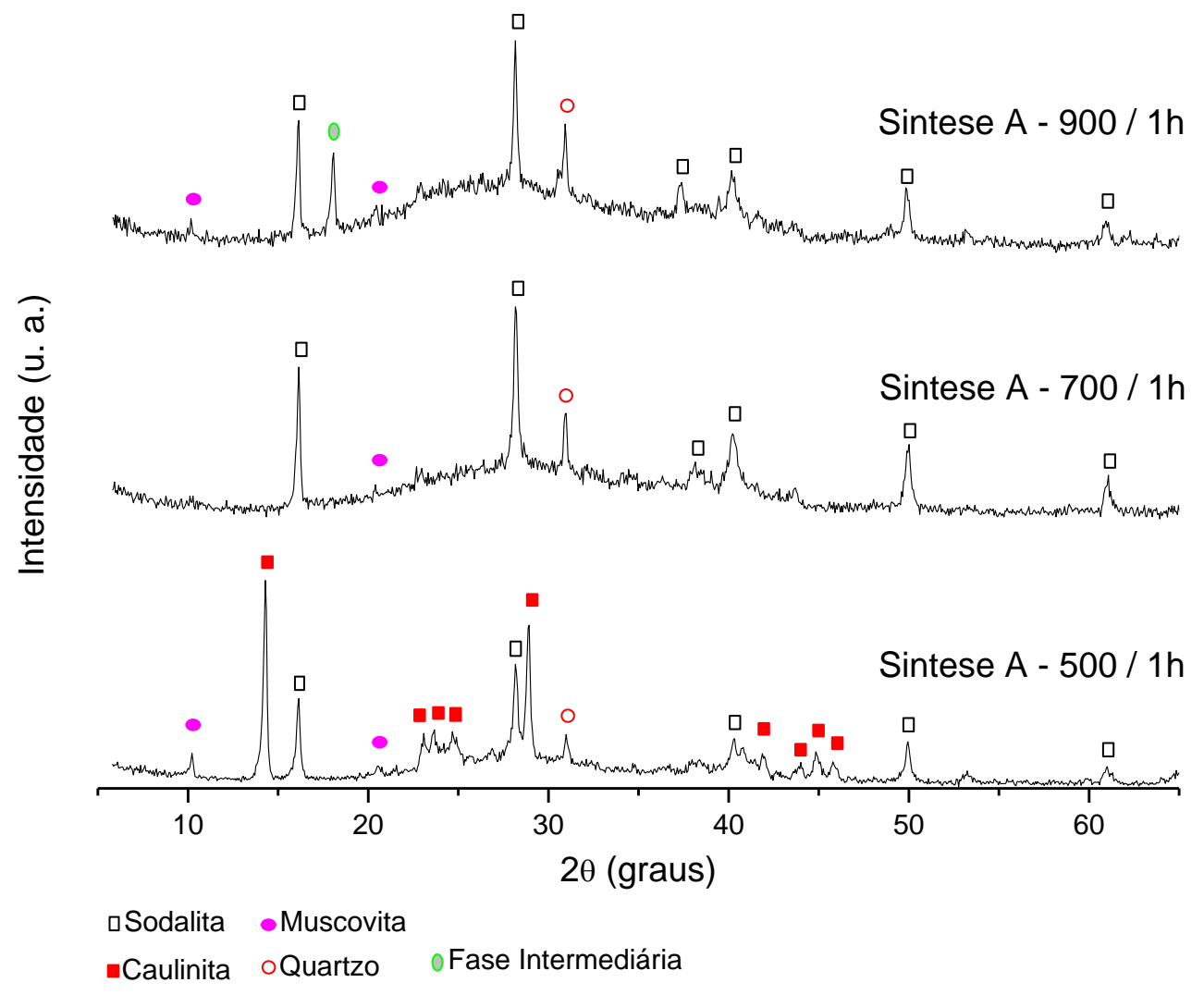

Figura 2: Difratogramas de raios $X(C o K \alpha)$ dos produtos da síntese $A$, por $1 \mathrm{~h}$, com o uso dos caulins calcinados a 500,700 e $900^{\circ} \mathrm{C}$.

Os resultados de DRX para os produtos da Síntese A, por $4 \mathrm{~h}$, conatam na Figura 3 . Ao comparar esses resultados com os das sínteses realizadas em 1 hora (Figura 2), observa-se que os picos referentes à sodalita são mais definidos e finos, nas sínteses no qual o tempo foi maior (Figura 3), indicando que um maior tempo de tratamento hidrotérmico favorece a formação da fase sodalita com um maior grau de cristalinidade. 


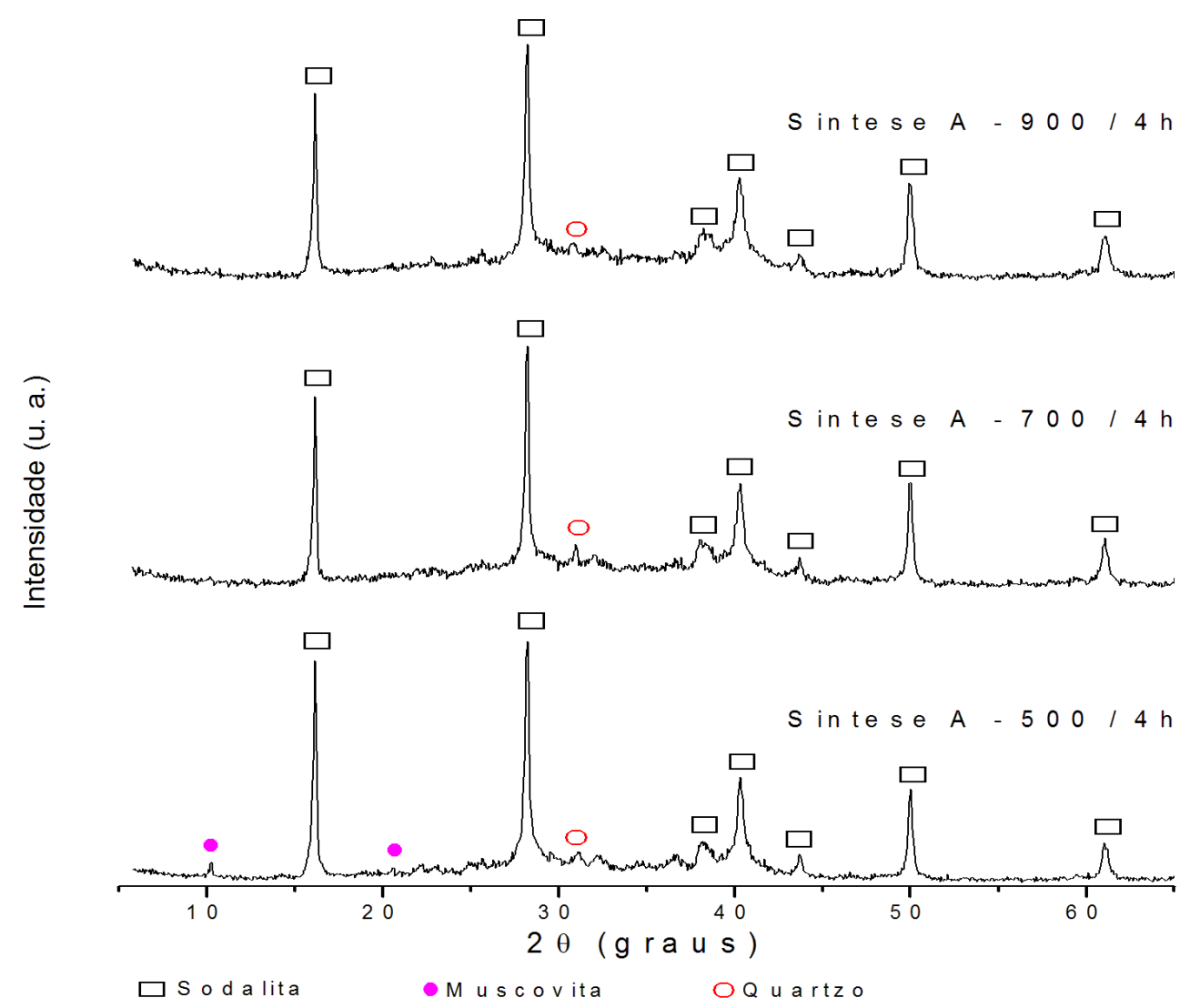

Figura 3: Difratogramas de raios $X(C o K \alpha)$ dos produtos da síntese $A$, por $4 \mathrm{~h}$, com o uso dos caulins calcinados a 500,700 e $900^{\circ} \mathrm{C}$.

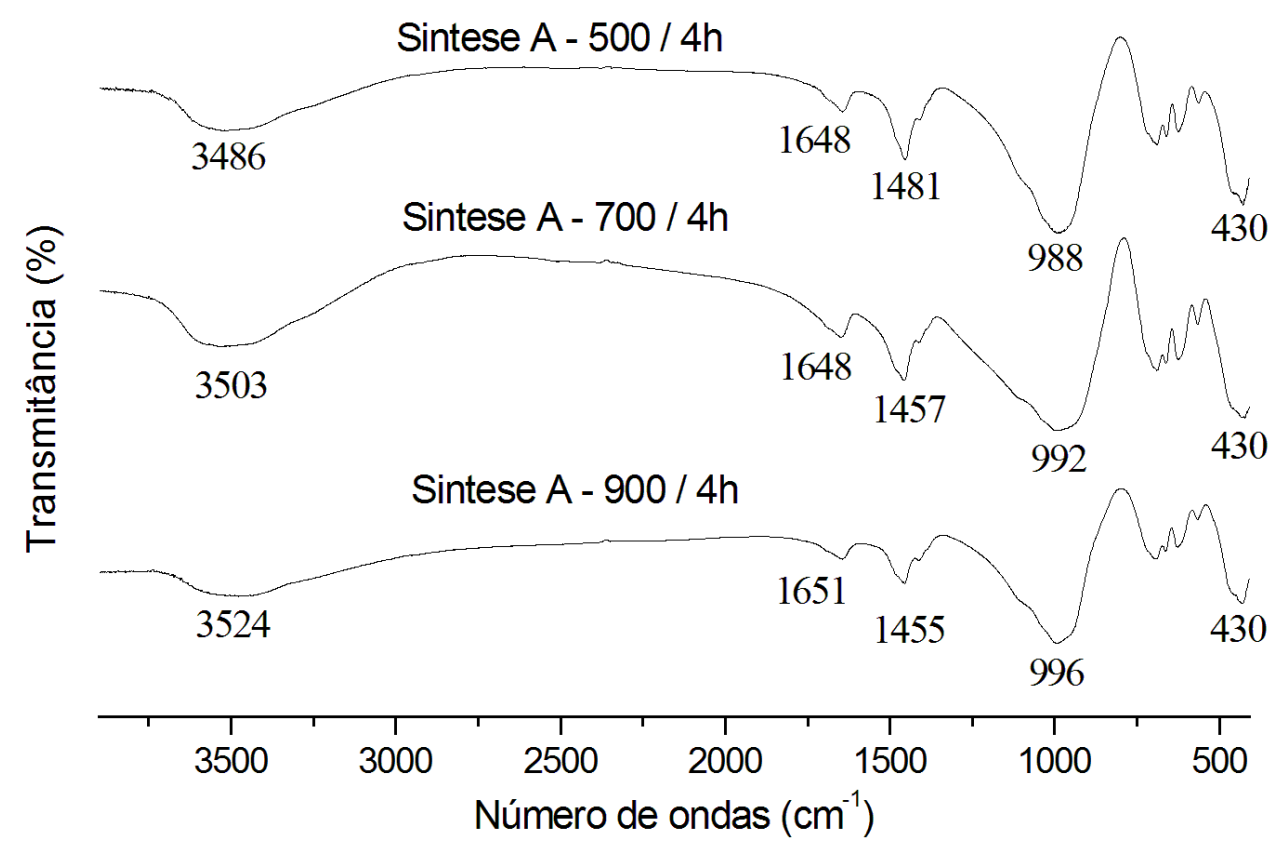

Figura 4: Espectros no infravermelho dos produtos da síntese A, por 4 h, com o uso dos caulins calcinados a 500 , 700 e $900^{\circ} \mathrm{C}$. 
Para complementar o estudo por DRX as amostras da Síntese A, por $4 \mathrm{~h}$, foram caracterizadas por espectroscopia no infravermelho, Figura 4. Nos espectros, são observadas as bandas relacionadas à sodalita, ao redor de $990,690,660,560,430 \mathrm{~cm}^{-1}$ (HELLER-KALLAI e LAPIDES, 2007, PAZ et al., 2010), não sendo observadas bandas relacionadas a outras fases, como a fase intermediária ou a zeólita $A$. Estes resultados confirmam a boa pureza da fase sodalita obtida, uma vez que, a DRX (Figura 3) indica apenas a existência de pequena quantidade de quartzo ou muscovita, nessas sínteses.

Dentre as espécies contidas dentro das cavidades da sodalita estão os grupos $\mathrm{OH}$, bandas entre 3.400 e $3.600 \mathrm{~cm}^{-1}$, moléculas de $\mathrm{H}_{2} \mathrm{O}$, banda próxima a $1.650 \mathrm{~cm}^{-1}$, e íons $\mathrm{CO}_{3}{ }^{2-}$, bandas entre 1.500 e $1.400 \mathrm{~cm}^{-1}$. As alterações observadas, na posição e na forma dessas bandas, podem ser atribuídas à formação da fase sodalita com diferentes graus de cristalinidade.

A micrografia do material obtido na Síntese A, por $4 \mathrm{~h}$, com o caulim calcinado a $700{ }^{\circ} \mathrm{C}$, Figura 5, comprova a formação da fase sodalita básica, cujas partículas, com formas arrendondadas, são características de aglomerados de policristais, que crescem e se aglomeram como novelos de lã (PAZ et al., 2010; GRADER e BUHL, 2013).

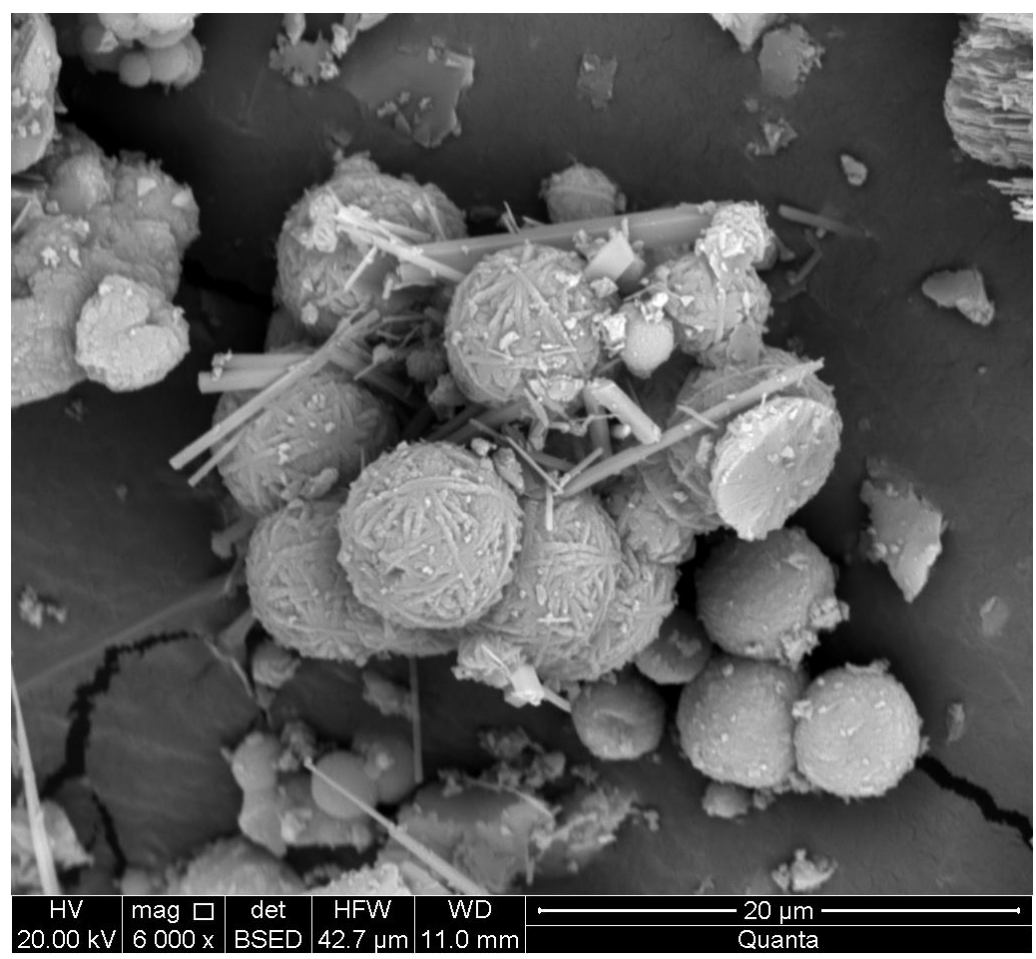

Figura 5: Micrografia do produto da Síntese A, com uso do caulim calcinado a $700{ }^{\circ} \mathrm{C}$ por $4 \mathrm{~h}$, obtida por meio da microscopia eletrônica de varredura.

Os produtos das sínteses por $1 \mathrm{~h}$, utilizando-se o caulim bruto, segundo os procedimentos das sínteses A e B, Tabela I, podem ser avaliados segundo dados da Figura 6. No caso da síntese A os resultados não foram satisfatórios, uma vez que, ocorreu a formação de uma mistura de fases, composta por sodalita, caulinita e muscovita. Para as condições da síntese B, observa-se apenas a existência das fases sodalita e muscovita. Este resultado indica que uma elevada concentração de $\mathrm{NaOH}$ aumenta notadamente a velocidade de formação da fase sodalita, mesmo quando se utiliza 
o caulim bruto, com baixa reatividade segundo a literatura (REYES et al., 20103). Entretanto, a muscovita não reage, permanecendo como impureza.

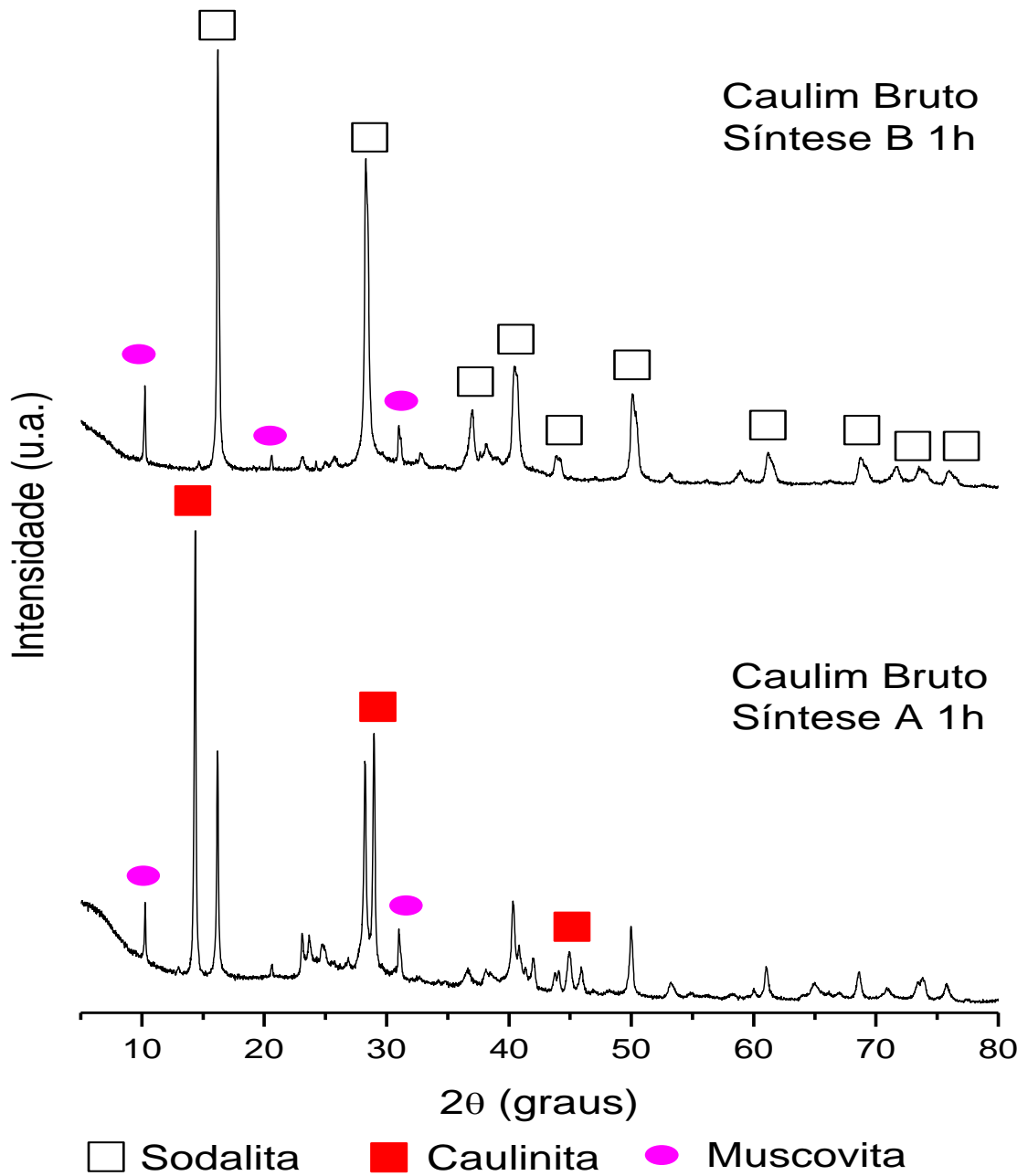

Figura 6: Difratogramas de raios X (Co K $\alpha)$ dos produtos de síntese do caulim bruto, Síntese A e Síntese B.

A transição da fase sodalita para a fase cancrinita foi observada na síntese $B$, com tempo de síntese de $4 \mathrm{~h}$, utilizando-se caulim previamente calcinado a $900^{\circ} \mathrm{C}$, Figura 7 . De acordo com os resultados, observa-se que a quantidade de $\mathrm{NaOH}$ utilizada foi determinante para a transição entre as fases, uma vez que a temperatura e o tempo de síntese foram os mesmos nos dois tipos de síntese, sendo que na síntese A observa-se apenas a presença da fase sodalita, como observado nas Figuras 2, 3 e 6 . Cabe ressaltar que resultados semelhantes foram obtidos em trabalho anterior, para as condições da Síntese A (SANTOS et al., 2012). Outro fator determinante foi a calcinação do caulim em temperatura elevada $\left(900^{\circ} \mathrm{C}\right)$, que tornou o alumínio e o silício mais disponíveis à síntese, acelerando o processo de transformação da fase sodalita para a fase cancrinita. De acordo com Maldonado et al a fase cancrinita é a estrutura termodinamicamente mais estável na temperatura de $170^{\circ} \mathrm{C}$ (MALDONADO et al., 2013). Portanto, é razoável se afirmar que a maior 
quantidade de $\mathrm{NaOH}$, na Síntese $\mathrm{B}$, foi responsável pelo aumento da velocidade de formação dessa fase.

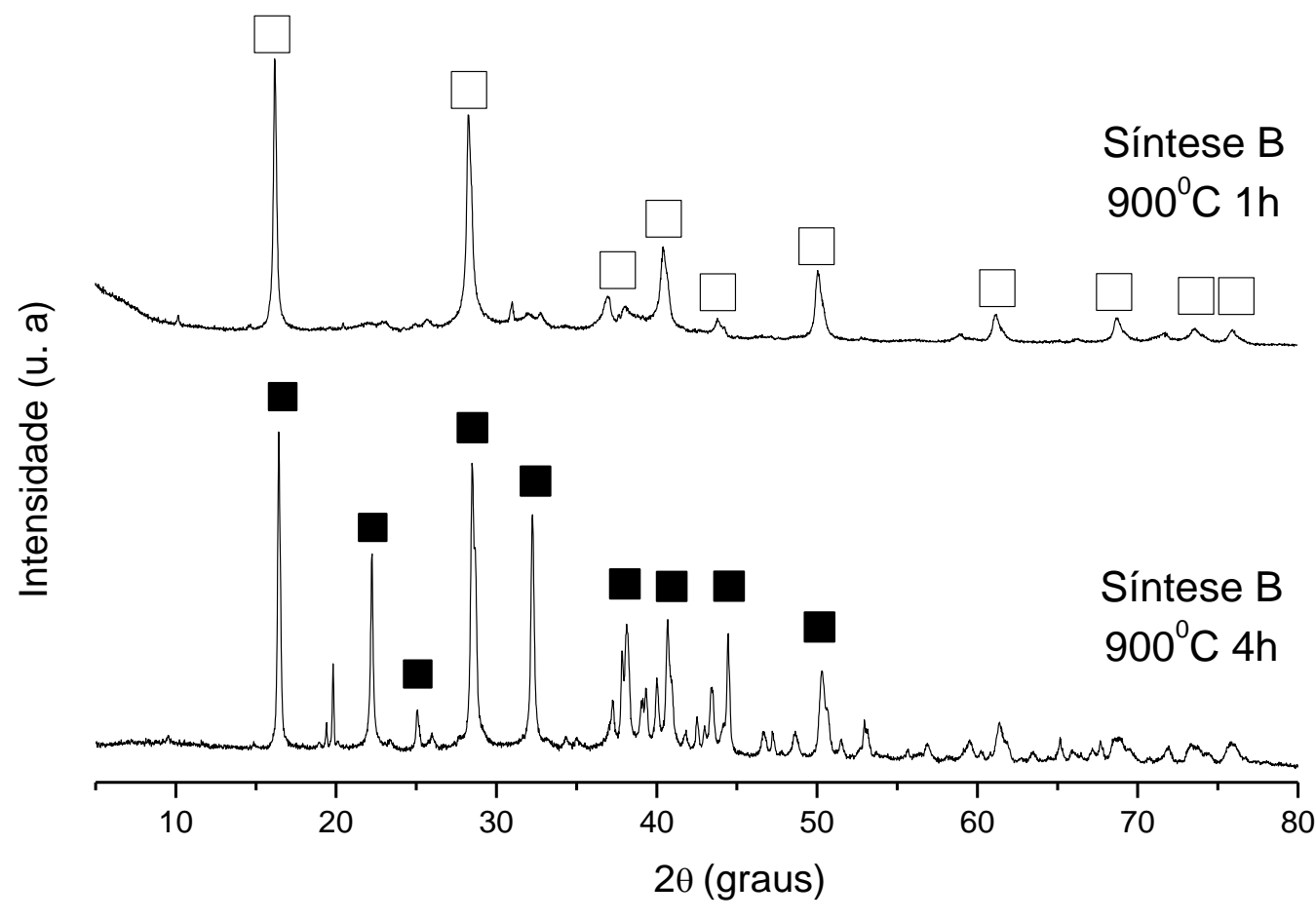

Sodalita Básica Cancrinita

Figura 7: Difratogramas de raios X (Co K $\alpha)$ dos produtos da síntese B, por 1 e $4 \mathrm{~h}$, com caulim calcinado a $900^{\circ} \mathrm{C}$.

\section{CONCLUSÕES}

A síntese da fase zeolítica sodalita básica com boa cristalinidade e com menor conteúdo de impurezas, para o caso da síntese $A$, é favorecida por meio da conversão da caulinita em metacaulinita, uma vez que, as sínteses com o caulim calcinado a 700 e $900^{\circ} \mathrm{C}$ foram bem sucedidas. Enquanto que, as sínteses com caulim calcinado a $500^{\circ} \mathrm{C}$ e com o bruto, com tratamento hidrotérmico por $1 \mathrm{~h}$, não foram satisfatórias, observando-se à formação de uma mistura de fases. $\mathrm{O}$ aumento da concentração de $\mathrm{NaOH}$, na síntese $\mathrm{B}$, resulta em uma maior velocidade de formação da sodalita, que pode ser obtida de forma quase pura, mesmo quando se utiliza o caulim bruto, nas sínteses com $1 \mathrm{~h}$. A transição entre as fases sodalita e cancrinita está diretamente relacionada ao tempo de tratamento hidrotérmico e a quantidade de $\mathrm{NaOH}$ utilizada na síntese.

\section{AGRADECIMENTOS}

Os autores agradecem a FAPERJ pelo auxílio financeiro (Processo: INST - 110.794/2012).

\section{REFERÊNCIAS BIBLÍOGRAFICAS}

1. AGUIAR, M.R.M.P.; NOVAES, A.C.; GUARINO, A.W.S., Remoção de metais pesados de efluentes 
industriais por aluminossilicatos, Química Nova, v. 25, p. 1145-1154, 2002.

2. GRADER, C.; BUHL, J.C.; The intermediate phase between sodalite and cancrinite: Synthesis of nano-crystals in the presence of $\mathrm{Na2CO} / \mathrm{TEA}$ and its thermal- and hydrothermal stability, Microporous and Mesoporous Materials, v. 171, p. 110-117, 2013.

3. HELLER-KALLAI, L.; LAPIDES, I. Reactions of Kaolinites and metakaolinites with $\mathrm{NaOH}$ comparison of different samples (Part 1). Applied Clay Science, v. 35, p. 99-107, 2007.

4. MALDONADO, M.; OLEKSIAK, M.D.; CHINTA, S.; RIMER, J.D.; Controlling Crystal Polymorphism in Organic-Free Synthesis of Na-Zeolites, Journal of the American Chemical Society, v. 135, p. 2641-2652, 2013.

5. MIGNONI, M.L., Zeólitas obtidas com líquidos iônicos como direcionadores de estrutura: síntese e reatividade. Porto Alegre, 2011. Tese de Doutorado - Instituto de Química, Universidade Federal do Rio Grande do Sul, 2011.

6. SILVA, F.A.N.G.; GARRIDO, F.M.S.; MEDEIROS, M.E.; SAMPAIO, J.A.; LUZ, A.B.; MELLO, L.D.S.; SILVA, F.T.; Alvejamento Químico de Caulins Brasileiros: Efeito do Potencial Eletroquímico da Polpa e do Ajuste do pH. Química Nova, v. 34, n. 2, p. 262-267, 2011.

7. PAZ, S.P.A.; ANGÉLICA, R.S.; NEVES, R.F.; Síntese Hidrotermal de Sodalita a partir de um Rejeito de Caulim Termicamente Ativado. Química Nova, v. 33, n. 3, p. 579-583, 2010.

8. SANTOS, C.G.M.; LANA, P.M.P.B.; SILVA, A.A.S.; BARBATO, C.N.; SAMPAIO, J.A.; GARRIDO, F.M.S.; SILVA, F.A.N.G.; Sintese da Fase Sodalita com o Uso do Caulim da Região BorboremaSeridó (RN/PB) Ativado Termicamente, Holos, v. 28, n. 5, 52-59, 2012.

9. REYES, C.A.R.; WILLIAMS, C.; ALARCÓN, O.M.C.; Nucleation and Growth Process of Sodalite and Cancrinite from Kaolinite-rich Clay under Low-temperature Hydrothermal Conditions, Materials Research, v.16, n. 2, p. 424-438, Feb. 2013.

10. SHINZATO, M.C., Remoção de Metais Pesados em Solução por Zeólitas Naturais: Revisão Crítica, Revista do Instituto Geológico, v. 27-28, p. 65-78, 2007.

11. SILVA, F.A.N.G.; Estudo de Caracterização e Beneficiamento do Caulim da Região BorboremaSeridó (RN). Rio de Janeiro, 2007. Dissertação de mestrado, PEMM/COPPE Universidade Federal do Rio de Janeiro, 2007.

12. SILVA FILHO, E.B., ALVES, M.C.M. e MOTTA, M., Lama vermelha da indústria de beneficiamento de alumina: produção, características, disposição e aplicações alternativas, Revista Matéria, v. 12, n. 2, p. 322-338, 2007.

13. www.iza-online.org, consultado em dezembro de 2013.

14. webmineral.com, consultado em dezembro de 2013.

15. Crystmet em www. periodicocapes.com.br, consultado em dezembro de 2013. 